
John J. Foxe

\title{
Visual sensory processing deficits in Schizophrenia and their relationship to disease state
}

Received: 8 November 2007 / Accepted: 17 January 2008 / Published online:

Abstract Context Visual Evoked Potential (VEP) abnormalities have been a fairly consistent finding in patients with schizophrenia, and it has been suggested that electrophysiological markers of early sensory processing may be useful as trait markers for the illness, and for development as potential diagnostic measures. Objective Clear amplitude reductions in the occipital P1 component of the VEP $(\sim 100 \mathrm{~ms})$, have been repeatedly demonstrated in patients with schizophrenia. Here, we investigated whether the extent of this deficit was related to age, clinical symptoms, medication status and length of illness, in a large cohort of ethnically homogenous patients. Design, setting and participants VEP responses to simple isolated-check stimuli were examined in 52 DSM-IV diagnosed

\footnotetext{
S. Yeap, MRCPsych $\cdot$ S.P. Kelly, $\mathrm{PhD} \cdot$ P. Sehatpour, $\mathrm{MD}, \mathrm{PhD}$

E. Magno, $\mathrm{PhD} \cdot$ H. Garavan, $\mathrm{PhD} \cdot$ J.H. Thakore, $\mathrm{MD}, \mathrm{PhD}$

J.J. Foxe, $\mathrm{PhD}$

The Cognitive Neurophysiology Laboratory

St. Vincent's Hospital

Richmond Road, Fairview

Dublin 3, Ireland

S. Yeap, MRCPsych · S.P. Kelly, PhD - P. Sehatpour, MD, PhD

J.J. Foxe, PhD ( $\square)$

The Cognitive Neurophysiology Laboratory

Nathan S. Kline Institute for Psychiatric Research

Program in Cognitive Neuroscience and Schizophrenia

140 Old Orangeburg Road

Orangeburg, NY 10962, USA

Tel.: 1-845/398-6547

Fax: 1-845/398-6545

E-Mail: foxe@nki.rfmh.org

E. Magno, $\mathrm{PhD} \cdot$ H. Garavan, $\mathrm{PhD} \cdot$ J.H. Thakore, $\mathrm{MD}, \mathrm{PhD}$

J.J. Foxe, PhD

Department of Psychology, Trinity College

Trinity College Institute of Neuroscience

Dublin 2, Ireland

J.J. Foxe, $\mathrm{PhD}$

Program in Cognitive Neuroscience

Department of Psychology

City College of the City University of New York

138th Street \& Convent Avenue

New York, NY 10031, USA
}

patients with schizophrenia, and compared with responses from 26 healthy age-matched control subjects. Using high-density electrical scalp recordings, we assessed the integrity of the visual P1 component across the two groups. This study was conducted at St.Vincent's Psychiatric Hospital in Fairview, Dublin, Ireland. Results Substantially reduced P1 amplitude was demonstrated in the patient group compared to controls. The deficit was not linked to age, length of illness or medication status. A small positive correlation, accounting for about $11 \%$ of the variance, was found between P1 amplitude and clinical symptoms scales (BPRS and SANS). In addition, we found that a slightly later $(\sim 110 \mathrm{~ms})$ fronto-central component was relatively increased in the patient group, and was inversely correlated with the occipital P1 amplitude in the patients, but not in the healthy control subjects. Conclusions Our findings clearly demonstrate a deficit in early visual processing in patients with schizophrenia (with a large effect size; Cohen's $d=0.7$ ) that is unrelated to chronicity. The results are consistent with recent findings showing that the $\mathrm{P} 1$ deficit is endophenotypic of the disorder and related to genetic risk factors rather than the disease process itself.

Key words visual-evoked potential · VEP · ERP · P1 deficit · schizophrenia - Ireland · hyperfrontality

\section{Introduction}

The P1 component of the VEP, with a peak latency typically varying between 75 and $110 \mathrm{~ms}$, is considered an index of early visual sensory processing [49]. It is topographically distributed over the midline and lateral occipital scalp regions, and is widely considered to arise from extrastriate visual areas [24, 42]. The $\mathrm{P} 1$ is robustly observable across individuals and easily and quickly measured non-invasively in just a

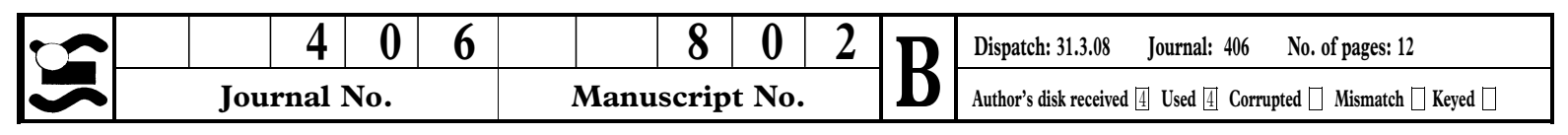


matter of minutes [36]. Because it reflects relatively automatic basic sensory processing, the P1 can be measured during a wide variety of tasks, and is not susceptible to motivational issues. It has consistently been described in patients with schizophrenia and, in the vast majority of cases, the amplitude of the P1 in patients has been found to be less than half the strength seen in healthy control subjects. More recently, a similar deficit has been demonstrated in non-psychotic first-degree relatives (see Table 1B).

An association between the reduced P1 amplitude and impairment in the magnocellular $(\mathrm{M})$ pathway has also been drawn $[7,9,23]$ and evidence from behavioural studies has also pointed to impairments in this system $[33,45,57)$. The $M$ pathway is the part of the visual system responsible for the rapid conduction of low-resolution visual information to the cortex and is involved in processing of overall stimulus organization $[46,62,66]$. Looking at the underlying processes involved in generating the deficit allows better understanding of the mechanisms of early stage visual processing and their putative relationship to subsequent higher-order cognitive processes in schizophrenia.

There are, to our knowledge, a total of twenty-six studies to date that have recorded the visual P1 in chronic patients with schizophrenia (see Table 1A). A large majority of these studies have also shown P1 deficits although eight of the twenty-six did not. The finding of the P1 deficit has been most consistent in our group of studies in chronic patients in New York $[7-9,21,23,26,56]$ although more recently, a number of other groups have shown similar deficits $[16,28$, 59]. However, only a few of these studies have examined the relationship between these early processing deficits and disease state. The present study uses the technique of high-density electrical mapping to record the visual evoked potential (VEP) in a large Irish cohort of patients with chronic schizophrenia $(N=52)$. Our main goal here was to record from a large enough sample to test for correlations of the P1 component with variables such as age, length of illness, medication and symptom scales. This study was carried out in Ireland, which has the advantage of a relatively homogeneous population compared with other countries in Europe.

In this study, we defined length of illness as the date of first presentation to the psychiatric services until the time of testing. This was standardised for all the patients via detailed examination of existing medical records. This measure does not, of course, take into account the duration of untreated psychosis (DUP) $[14,15]$, which is defined as the time from manifestation of the first psychotic symptoms to initiation of adequate treatment. Adequate treatment is defined as the taking of antipsychotic medication for a period of 1 month or until significant response was

Table 1 Studies investigating the P1 deficit in (A) patients with schizophrenia and (B) unaffected first-degree relatives

\begin{tabular}{|c|c|c|c|c|c|}
\hline Authors & Journal & Year & Patients & Controls & P1 deficit found \\
\hline \multicolumn{6}{|l|}{ (A) } \\
\hline Mukundan & Biol Psychiatry & Sep-1986 & 29 & 29 & $\checkmark$ \\
\hline Romani et al. & Acta Psychiatr Scand & May-1986 & 18 & 35 & $\checkmark$ \\
\hline Matsuoka et al. & Electroencep Clin Neurophys & Jan-1996 & 15 & 15 & 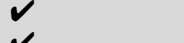 \\
\hline Basinska et al. & Acta Neurobiol Exp (Wars) & Nov-1998 & 50 & 50 & 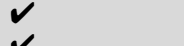 \\
\hline Foxe et al. & Neuroreport & Dec-2001 & 14 & 16 & $\checkmark$ \\
\hline Doniger et al. & ArchGen Psych & Nov-2002 & 16 & 16 & $\checkmark$ \\
\hline Spencer et al. & J Neurosci & Aug-2003 & 12 & 12 & $\checkmark$ \\
\hline Schecter et al. & Schizophr Res & Nov-2003 & 20 & 18 & $\checkmark$ \\
\hline Clementz et al. & Cognitive Brain Res & Jan-2004 & 12 & 12 & $\checkmark$ \\
\hline Spencer et al. & Proc Natl Acad Sci U S A & Dec-2006 & 20 & 20 & $\checkmark$ \\
\hline Butler et al. & Arch Gen Psych & May-2005 & 33 & 21 & $\checkmark$ \\
\hline Kim et al. & Schizophr Res & Jul-2005 & 26 & 22 & $\checkmark$ \\
\hline Schecter et al. & Clin Neurophysiol & Sep-2005 & 74 & 59 & 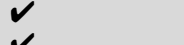 \\
\hline Foxe et al. & Cereb Cortex & Dec-2005 & 16 & 17 & $\checkmark$ \\
\hline Butler et al. & Brain & Sep-2006 & 23 & 19 & $\checkmark$ \\
\hline Yeap et al. & Arch Gen Psych & Nov-2006 & 15 & 26 & $\checkmark$ \\
\hline Haenschel et al. & Arch Gen Psych & Nov-2007 & 12 & 12 & $\checkmark$ \\
\hline Lalor EC et al. & Schizophr Res & Jan-2008 & 13 & 11 & $\checkmark$ \\
\hline Strandburg et al. & Psychophysiology & May-1994 & 18 & 19 & $\times$ \\
\hline Katsanis et al. & Psychophysiology & May-1996 & 43 & 113 & $\times$ \\
\hline Van Sweden et al. & Acta Neurol Belg & Mar-1998 & 38 & NA & $\times$ \\
\hline Bruder et al. & J Abnorm Psychol & Aug-1998 & 28 & 28 & $\times$ \\
\hline Alain et al. & Biol Psychiatry & Dec-1998 & 15 & 15 & $\times$ \\
\hline van der Stelt et al. & Archives of Gen Psych & Mar-2004 & 22 & 22 & $\times$ \\
\hline Johnston et al. & Eur J Nuerosci & Sep-2005 & 11 & 15 & $x$ \\
\hline Sponheim et al. & Biol Psychiatry & Aug-2006 & 23 & 23 & $\times$ \\
\hline \multicolumn{5}{|l|}{ (B) } & P1 deficit found \\
\hline Katsanis et al & Psychophysiology & May-1996 & 50 & 113 & $\times$ \\
\hline Sponheim et al & Biol Psychiatry & Aug-2006 & 28 & 23 & $x$ \\
\hline Yeap et al & Arch Gen Psych & Nov-2006 & 25 & 26 & $\checkmark$ \\
\hline
\end{tabular}

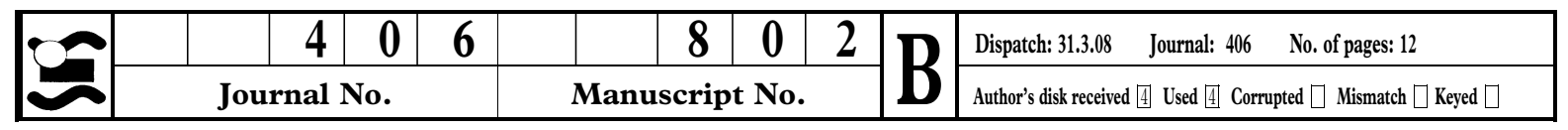


achieved or whichever came first [41]. It is worth noting here that DUP measures are notoriously difficult to obtain and standardise and it was simply not possible to include accurate estimates of this measure in our calculations.

With few studies actually correlating VEP measures to symptom and functional outcome scales [16, 56], we also sought to examine the relationship between the P1 deficit and clinical features of schizophrenia as measured by the brief psychiatric rating scale (BPRS) [51] and the scale for the assessment of negative symptoms (SANS) [2].

\section{Materials and methods}

\section{Subjects}

Written informed consent was obtained from 52 (17 female) patients with schizophrenia, aged 19-64 years (mean \pm SD $=41.8 \pm$ 12.8 years), from the St. Vincent's Hospital Catchment Area, Dublin, Ireland. All procedures were conducted in accordance with the ethical standards laid down in the 1964 Declaration of Helsinki. All patients were of white Caucasian Celtic extraction. All patients met DSM-IV criteria for schizophrenia. The mean \pm SD score in the BPRS [51] and the scale of assessment of negative symptoms (SANS) [2] were $37.84 \pm 9.81$ and $38.26 \pm 26.02$, respectively. The mean $\pm \mathrm{SD}$ chlorpromazine dose was $410 \pm 331 \mathrm{mg} /$ day and medications comprised of typical and atypical antipsychotics. The mean \pm SD length of illness was $14.4 \pm 9.5$ years. Control subjects comprised 26 (13 female) paid volunteers aged 21-64 years, (mean $\pm \mathrm{SD}=38.7 \pm 12.6$ years) recruited from the St. Vincent's Hospital Staff Community and the local hospital catchment area. The mean age of patients and controls did not differ significantly $[t(75)=1.38, P=0.37]$. Forty-four of the 52 patients and 21 of the 26 controls were right-handed as assessed by the Edinburgh Handedness Inventory [50]. All subjects reported normal or corrected-to-normal vision. Controls were medication-free and free of any psychiatric illness or symptoms by self-report using criteria from the SCID-NP [60] and reported no history of alcohol or substance abuse. All procedures were approved by the St. Vincent's Hospital Ethics Committee.

\section{Stimuli and task}

In each experimental block, subjects were presented with around 100 isolated check images, grey on a white background $\left(4^{\circ} \times 4^{\circ}\right.$ visual angle) at $64 \%$ contrast, and 40 line drawings of 2 kinds of animal $\left(2.4^{\circ}\right.$ wide $\times 1.8^{\circ}$ high $)$ on a white background [68]. Each block contained a different animal pair from a possible 22 . The $64 \%$ contrast condition was chosen to stimulate both the magnocellular (M) and parvocellular (P) systems. On average, subjects completed 13.5 (10-15) blocks, each lasting $3 \mathrm{~min}$. Stimuli were presented centrally on a CRT computer monitor in random order with the monitor located $160 \mathrm{~cm}$ directly in front of the seated subjects.

The timing of the presentations was such that each image appeared for $60 \mathrm{~ms}$ with a variable inter-stimulus interval (ISI) between 740 and $1540 \mathrm{~ms}$ (randomly in steps of $200 \mathrm{~ms}$ ) during which there was a blank white screen. The target animal was displayed at the start of the task and the subjects were asked to respond each time this animal was presented by pressing a button with their right thumbs. They were told only to respond to target animals and to try to withhold responses to any other animal presented. The target and non-target animals were presented with equal probability, ensuring that a subject could not rely on the exogenous alerting nature of any non-checkerboard stimulus to respond. Furthermore, the task of discrimination was made difficult by pairing similar-looking animals, e.g. a dolphin and a whale. The primary motivation for using this task rather than simply having subjects passively observe the standard stimuli was to ensure that subjects remained alert and fixated centrally on the screen throughout recording. Only ERPs to the standard check stimuli were included in the analysis.

\section{Data acquisition and statistical analysis}

Continuous electroencephalogram (EEG) data were acquired through the ActiveTwo Biosemi electrode system (BioSemi, Amsterdam, the Netherlands) from 72 scalp electrodes, digitised at $512 \mathrm{~Hz}$ with an open pass-band from DC to $150 \mathrm{~Hz}$. For analysis and display purposes, data were subsequently filtered with a $45 \mathrm{~Hz}$ low-pass filter ( $24 \mathrm{~dB} /$ octave; zero phase shift) after acquisition. All data were re-referenced to the nasion after acquisition for analysis.

Data were analyzed using BESA Version 5.08 (Brain Electric Source Analysis, Gräfelfing, Germany). All electrode channels were subjected to an artifact rejection criterion of $\pm 120 \mu \mathrm{V}$ from -200 to $500 \mathrm{~ms}$ to reject trials with excessive electromyogram (EMG) or other noise transients. The vertical and horizontal electro-oculograms were also visually inspected for blinks and large eye movements. Epochs were extracted with a time-window from $200 \mathrm{~ms}$ pre-stimulus to $500 \mathrm{~ms}$ post-stimulus, and baseline-corrected relative to the interval $-80-0 \mathrm{~ms}$. Accepted trials were then averaged for the isolated-check stimuli only. The mean \pm SD epoch acceptance rate for patients was $62.2 \pm 12.7 \%$ and for the control group it was $63.4 \pm 16.8 \%$. The average numbers of accepted trials were 678 for patients and 992 for controls.

A measure of $\mathrm{P} 1$ amplitude was defined as the area under the curve (relative to the $0 \mu \mathrm{V}$ baseline) in the interval 87-97 ms, spanning the P1 component, chosen based on grand average waveforms. These area measures were then submitted to a repeated-measures analysis of variance (ANOVA) with the between-subjects factor of group (patients vs. controls) and within-subjects factors of region (left/midline/right) and electrode $(\mathrm{O} 1 / \mathrm{PO} 7 / \mathrm{PO} 3, \mathrm{Oz} / \mathrm{POz} / \mathrm{Pz}, \mathrm{O} 2 / \mathrm{PO} 4 / \mathrm{PO} 8)$, covering the left lateral occipital, midline dorsal and right lateral occipital visual scalp regions respectively. All tests were two-tailed with a preset $\alpha$-level of $P<0.05$. Protected follow-up tests were conducted where appropriate.

To investigate whether P1 amplitude varies as a function of age, length of illness, medication status or clinical symptomatology, we conducted Pearson correlations using the data of the patient group only. In these analyses, the P1 was measured from the electrode showing the largest difference between groups, and hence the largest deficit. In this case, it was electrode site PO4.

Following our primary analysis of P1 amplitude, it was of interest to further investigate spatio-temporal properties of any potential differences between groups, using the statistical cluster plot method. This procedure has been used effectively in post-hoc analyses as a means to fully explore complex datasets and generate pointed follow-up hypotheses [47, 67]. Point-wise two tailed t-tests between patients and controls are calculated at each time point for all electrodes, and a colour map is subsequently generated marking time-points on each electrode for which the $t$ value exceeds that corresponding to a $0.05 P$ value. Here we plot positive and negative $t$ values in separate colour scales (green and gold) to distinguish differences in opposite directions. All nonsignificant points are represented as white.

\section{Results}

The mean \pm SD target hit rate (the percentage of correct responses) for the patients was $83.2 \pm 16.4 \%$ and $95.4 \pm 7.6 \%$ for the controls $(t(76)=4.46$, $P<0.001)$. The reason for measuring the target hit rate was to ensure that patients were focusing their attention on the screen. There was also a difference in

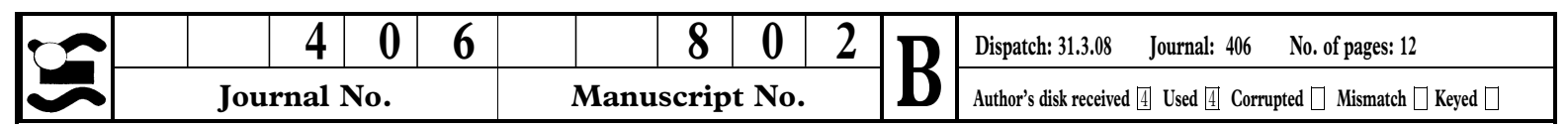


the percentage of false alarms (i.e. pressing for the non-target animals) where patients scores were $20.3 \pm 20.5 \%$ versus $6.4 \pm 4.5 \%$ for controls $(t(76)=$ 4.73, $P<0.001)$.

Figure 1 shows the ERP traces plotted for 6 selected electrodes across the scalp for both groups. As is typical, the P1 peak latency occurred around $90 \mathrm{~ms}$, with a bilateral topography over the posterior lateral-occipital scalp.

An omnibus ANOVA (2 groups $\times 3$ regions $\times 3$ electrodes) was used to compare the P1 amplitudes between both groups over the left lateral occipital, midline dorsal and right lateral occipital areas. The results showed a significant main effect of group $[F(1,76)=6.02, \quad P<0.02]$ indicating reduced $\mathrm{P} 1$ amplitude in the patient group compared to the controls. There were also significant effects of region $[F(2,76)=31.63, \quad P<0.001]$, electrode $[F(2,76)=$ 21.71, $P<0.001]$ and a region $\times$ electrode interaction $[F(2,76)=12.68, \quad P<0.001]$, reflecting the topographic specificity of the P1. The interactions of region $\times$ group $[F(1,152)=3.16, P<0.05]$ and region $\times$ electrode $\times$ group $[F(4,304)=3.24, P<0.02]$ were also significant, pointing to significant topographic differences in the distribution of the P1 between groups.
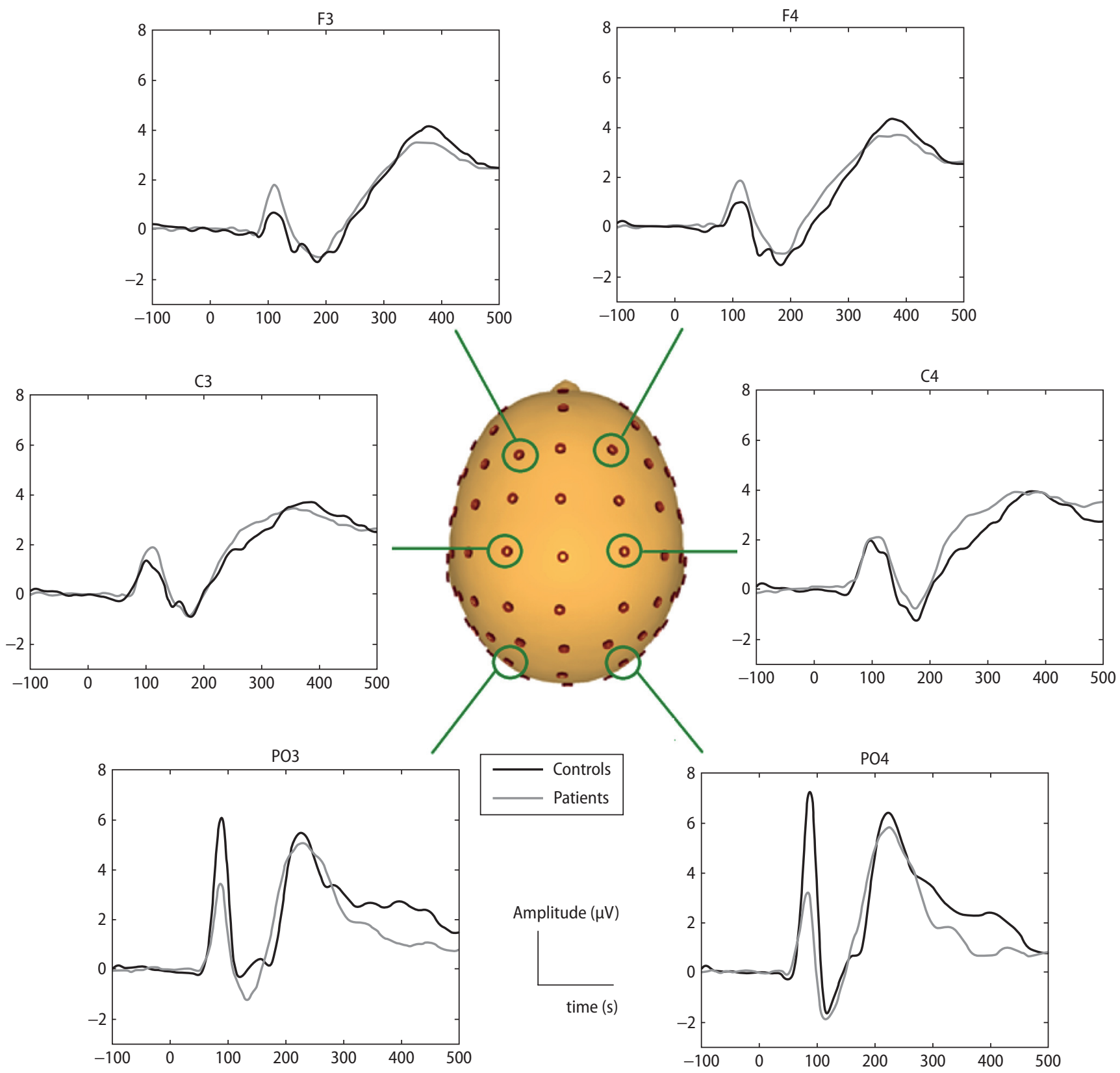

Fig. 1 Grand-average ERP traces at six selected electrodes across the scalp for the control and patient groups

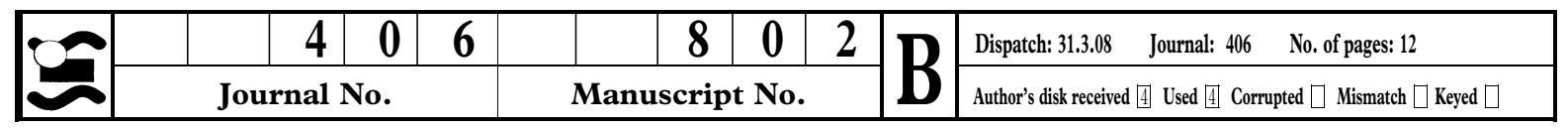




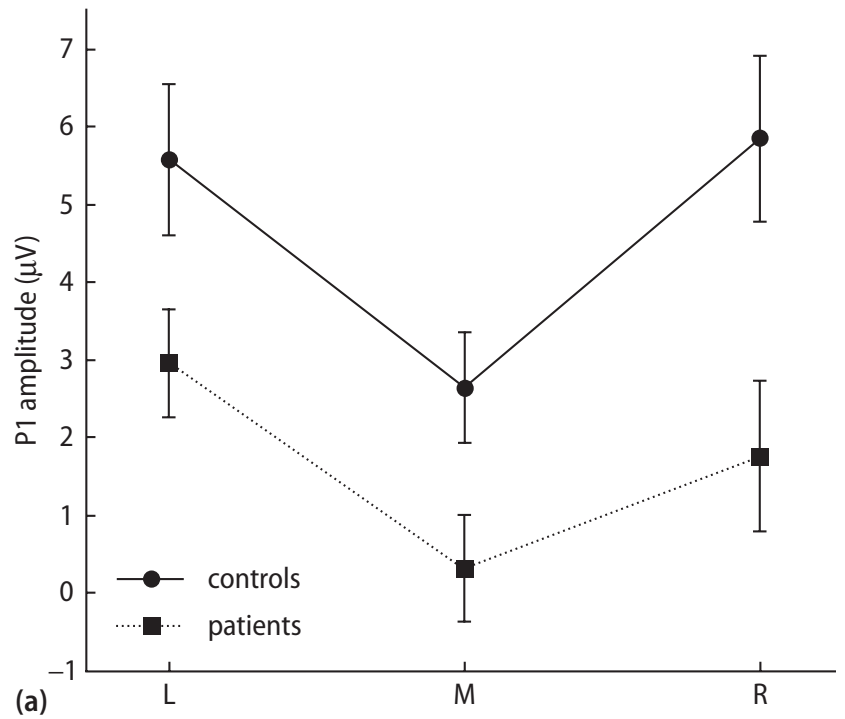

(a)
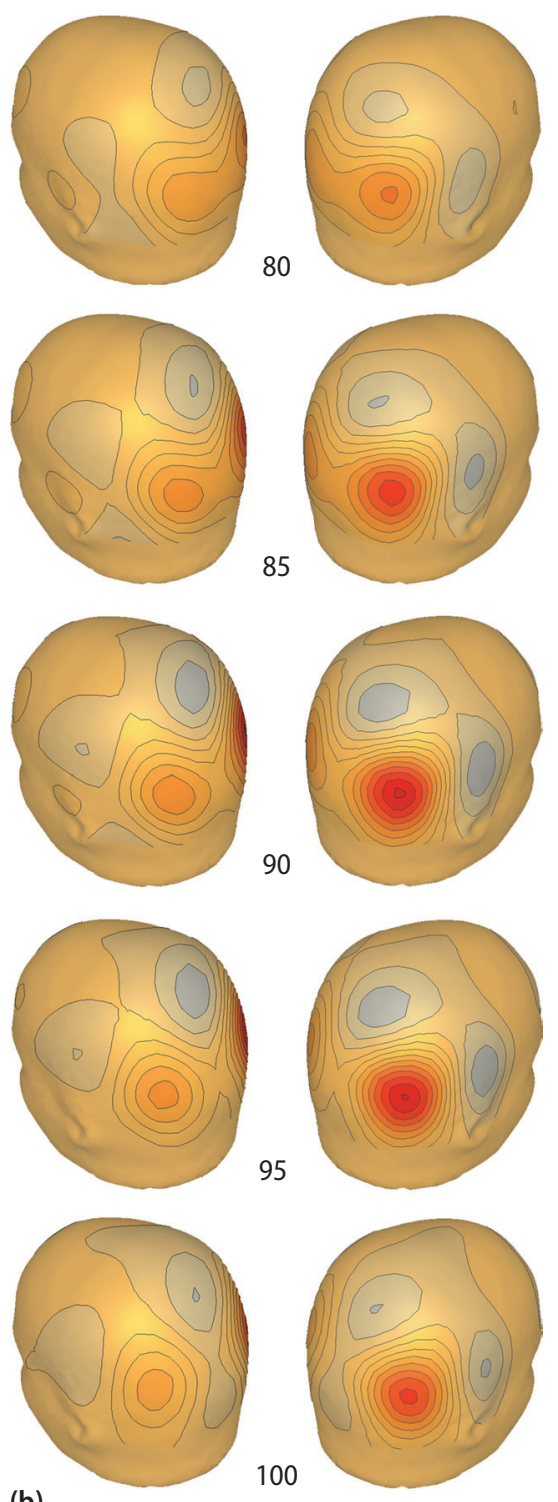

4Fig. 2 a P1 amplitude as a function of region (left hemisphere, midline and right hemisphere respectively), illustrating group $\times$ region interactions. b Current Source Density (CSD) difference topographies (controls minus patients) over the time frame of the P1 (80-100 ms). The deficit is clearly greater over the right hemisphere, with both dorsal and ventral projections. CSD mapping, as implemented in BESA [52], calculates the second spatial derivative of the scalp field potential, thus eliminating tangential current flow. This provides improved visualization of approximate locations of intracranial generators

Protected $2 \times 2$ ANOVAs were carried out to further explore the topography of this group effect, comparing each pairing of scalp regions in their turn, with data collapsed across electrodes. A marginal group $\times$ region interaction was found comparing the left and right hemisphere regions $(F(1,76)=3.22$, $P=0.08)$. A significant interaction was found comparing the right and midline regions $(F(1,76)=4.38$, $P=0.04)$, and no interaction comparing left to midline $(F(1,76)=0.27, P=0.61)$. The underlying pattern is illustrated in Fig. 2. Somewhat in contrast to previous studies where a midline focus for the relative reduction in P1 in patients was found [21, 23, 26], here the group effect appears greatest over right hemisphere sites. The current source density (CSD) difference topographies of Fig. $2 b$ demonstrate the stability of the right-hemisphere laterality of the deficit over time.

Figure 3 shows the distribution of $\mathrm{P} 1$ amplitude for all patients (each marked with an ' $x$ ') and controls (each marked with a ' + ') at the right hemisphere parieto-occipital scalp site PO4, where the P1 amplitude difference was maximal. The mean values are shown to the left of the individual values. There is

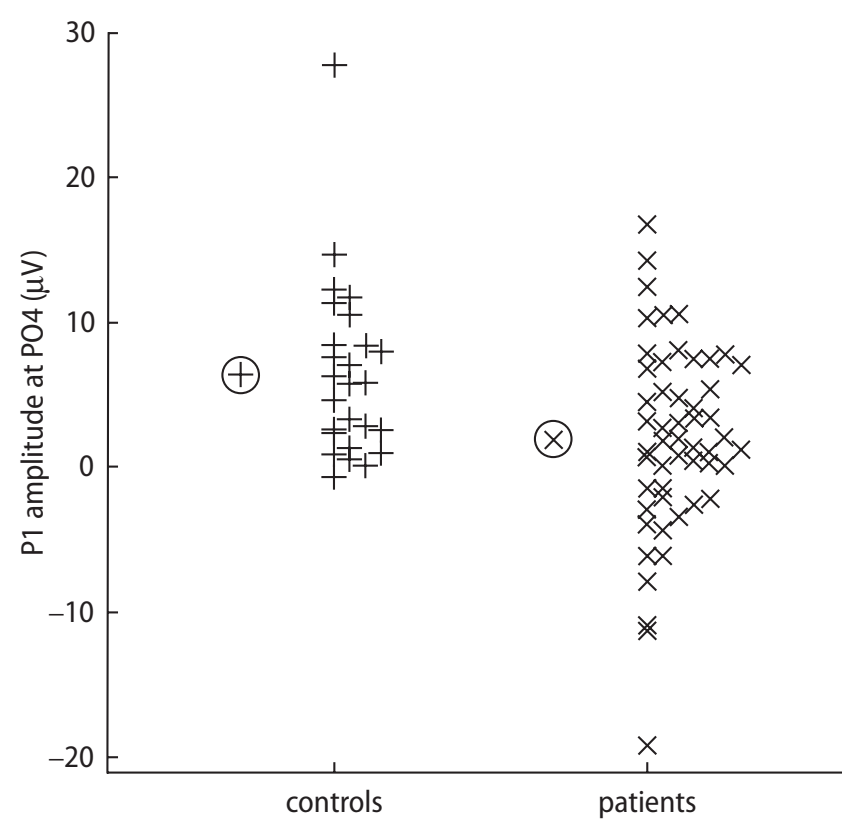

Fig. 3 Scatter Plot showing the distribution of P1 amplitudes in the controls $(+)$ and the patients $(x)$ with the mean values circled to the left of each distribution

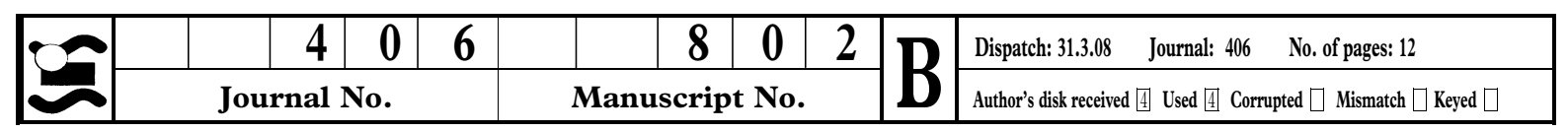


considerable overlap between the patient and control group distributions, with standard deviations for the controls and the patients at 6.07 and 6.61, respectively. The effect size was found to be 0.70 at this electrode, which is large according to Cohen's criterion [17].

There was no significant correlation between age and the P1 in patients $(r=0.21, P=0.14)$ (see Fig. $4 c$ ). There was a significant positive correlation between the P1 amplitude and negative symptoms (SANS) $(r=0.34, P=0.03)$ (see Fig. $4 \mathrm{a}$ ) as well as the BPRS $(r=0.34, P=0.03$ ) (see Fig. $4 \mathrm{~b})$. Further, P1 amplitude was not correlated with either length of illness $(r=-0.03, P=0.86)$ or medication status $(r=0.05, P=0.75)$ (Fig. $4 \mathrm{~d}$, e).

Figure 5 is the statistical cluster plot illustrating a posterior cluster in the time range of the $\mathrm{P} 1$, reflecting the group differences as reported in the ANOVA. Immediately following the P1 component, an increased positive activation was observed over frontal scalp in patients (see Fig. 1) The reader may note that an earlier difference at $\sim 50 \mathrm{~ms}$ over fronto-central scalp sites also reaches significance in the statistical cluster plot. As this effect was unpredicted and not observed in any previous studies to our knowledge, it must be treated with some caution for now until such time as it is replicated ${ }^{1}$ This may reflect increased recruitment of frontal brain regions similar to that found in recent studies [21, 26], albeit in an earlier time interval. "Hyperfrontality" in patients has been postulated to represent additional processing carried out in compensation for sensory deficits [26]. If this is indeed the case, then one might expect to find greater frontal activity in those patients exhibiting more deficient P1 amplitudes. To test whether the amplitude of the frontal positivity (here named 'P1f') in patients depends on the amplitude of the preceding posterior P1, a post-hoc correlation analysis was carried out. P1f was measured as the average amplitude in the interval $105-120 \mathrm{~ms}$ at fronto-central electrode site $\mathrm{FCz}$ where the increased activity relative to controls was maximal. As the full extent of these components may overlap both temporally and spatially, we controlled for biases arising from the choice of reference electrode by transforming the data to average-reference for this analysis. A significant negative correlation was found for the patient group $(r=-0.42 ; P=0.002)$ (Fig. 6a). As the frontal positivity is temporally coincident with the posterior N1 component, it might be argued that it reflects the same process, manifesting more faintly and with opposite polarity over frontal scalp. However, group differences are only observed for this frontal component, and not for the posterior $\mathrm{N} 1$, which is much larger and more robust and would therefore be expected to produce stronger effects. Moreover, if the correlation could simply be explained by physical factors relating to dipolar sources and referencing, then a similar correlation should be observed in the control group. When tested in the same way, no such correlation was found in control subjects $(r=0.06$; $P=0.78$ ) (Fig. 6b).

Following the suggestion of one reviewer, a series of post-hoc regression analyses were conducted to test whether the P1f, which was found here to differentiate between groups and to negatively correlate with the $\mathrm{P} 1$, might correlate with symptom scores, age, length of illness and medication status, and whether when combined in a multiple regression with the P1 measure, there might be an increase in explained variance for any of these factors. We found that P1f did not correlate with SANS, BPRS or with medication $(P>0.1)$. However, we found that age was significantly correlated with P1f amplitude $(r=0.28$, $P<0.05)$, and that when both the P1 and P1f measures were factored together, explained variance increased to $16.3 \%$ (compared to $7.9 \%$ for P1f alone). P1f also correlated with length of illness $(r=0.29$, $P<0.02)$.

\section{Discussion}

In patients with schizophrenia, significant impairments in early-stage visual processing, as indexed by reductions in the amplitude of the P1 component of the VEP, have now been repeatedly described (See Table 1A). In this context, it has been of particular importance to establish the general robustness of these impairments and whether they are pathognomonic of the disease. In the present study, we again found a substantial reduction in the P1 amplitude in 52 patients compared to healthy age-matched controls $(P=0.016)$ with a large effect size of $d=0.70$ (Cohen's Criteria). Together with our recent finding of a similar P1 deficit in unaffected first-degree relatives [68], the present finding of no effects of age, length of illness or medication dose, reinforces the view that these marked deficits in P1 are linked to the underlying genetic liability for schizophrenia rather than a function of the disease state itself [22]. As such, the P1 deficit appears to be a very promising candidate as an endophenotype for schizophrenia [27].

Of the 26 studies that have reported on the visual P1 component in patients with schizophrenia, fully 18 have recorded significant deficits. It is worth pointing out that in the bulk of the remaining eight studies where a P1 deficit was not observed, later cognitive potentials were typically the dependent measures of interest (e.g. P300) and the P1 findings were incidental to the main focus of these studies $[1,5,32,63$, 64, Johnston et al. 2005]. In some of these studies, there are very obvious reasons why a P1 deficit was not observed. For example, [32] used a very limited electrode montage, investigating only three central scalp electrode sites (C3, CZ, C4), sites where the P1 signal is highly attenuated if present at all. Another

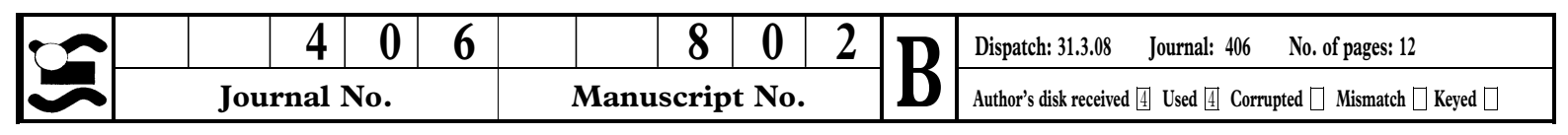



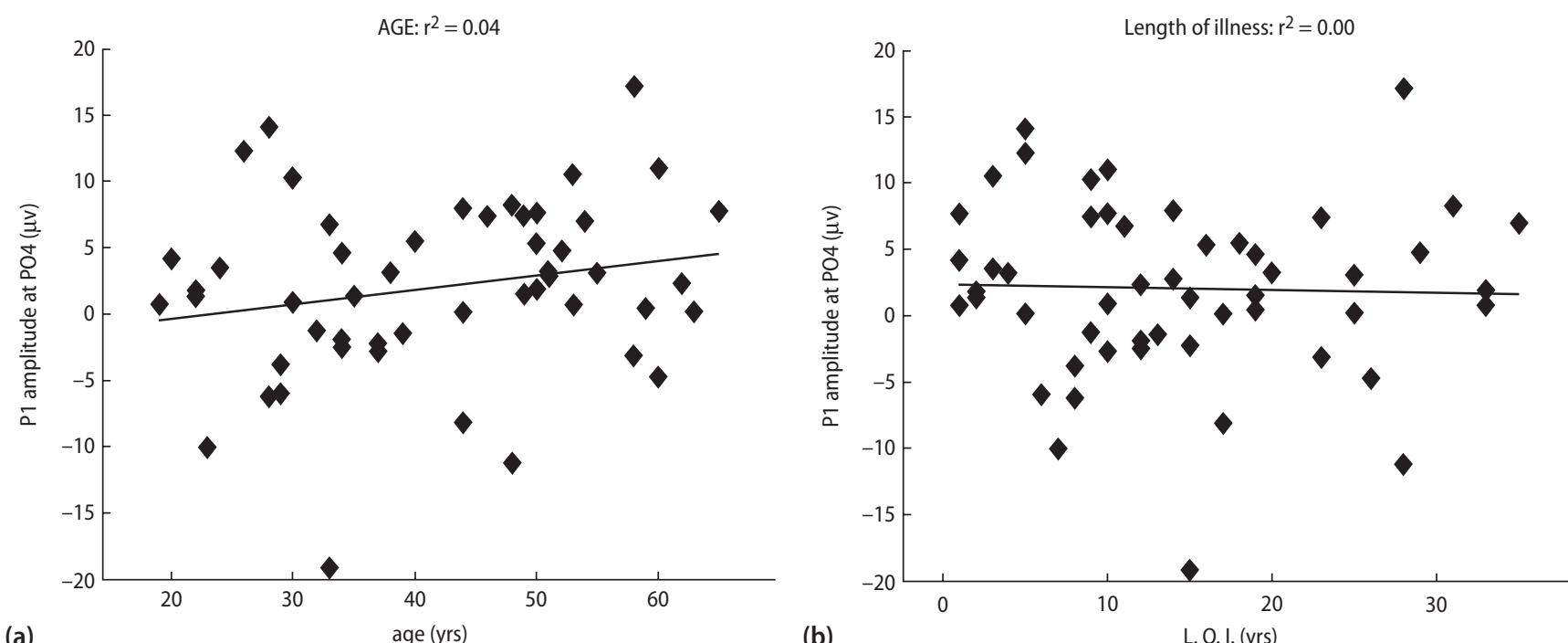

(a)

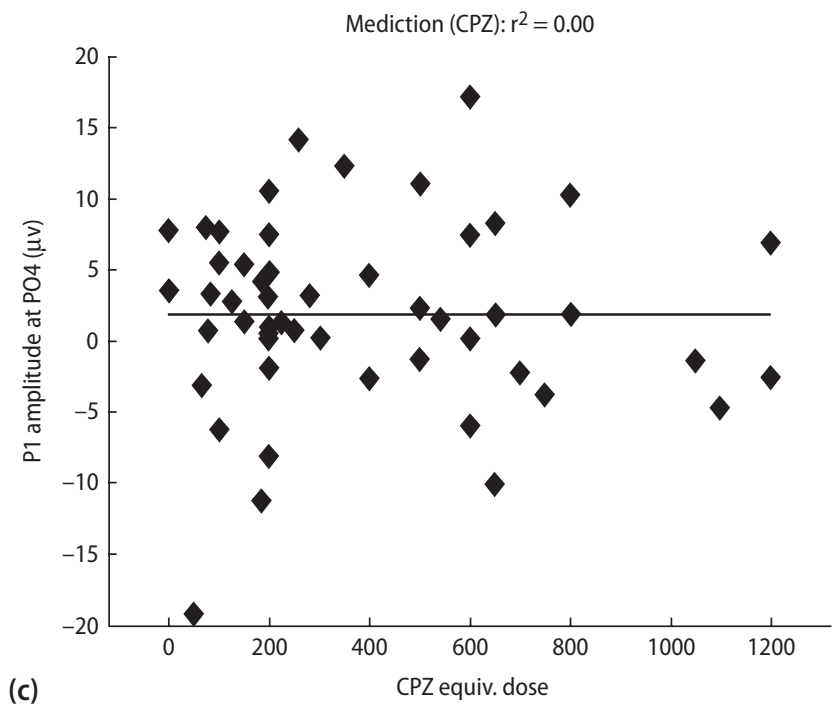

(b)

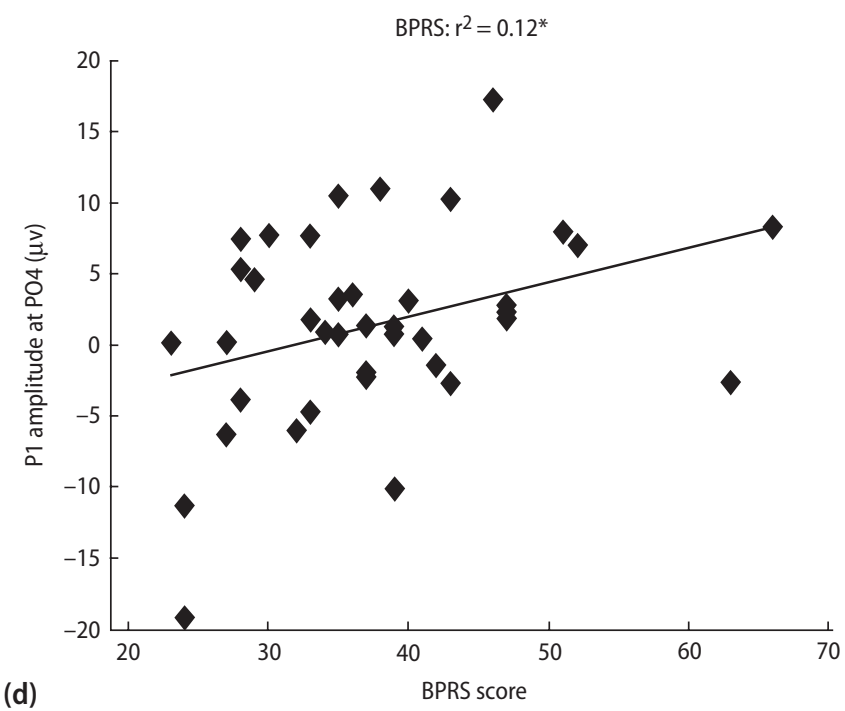

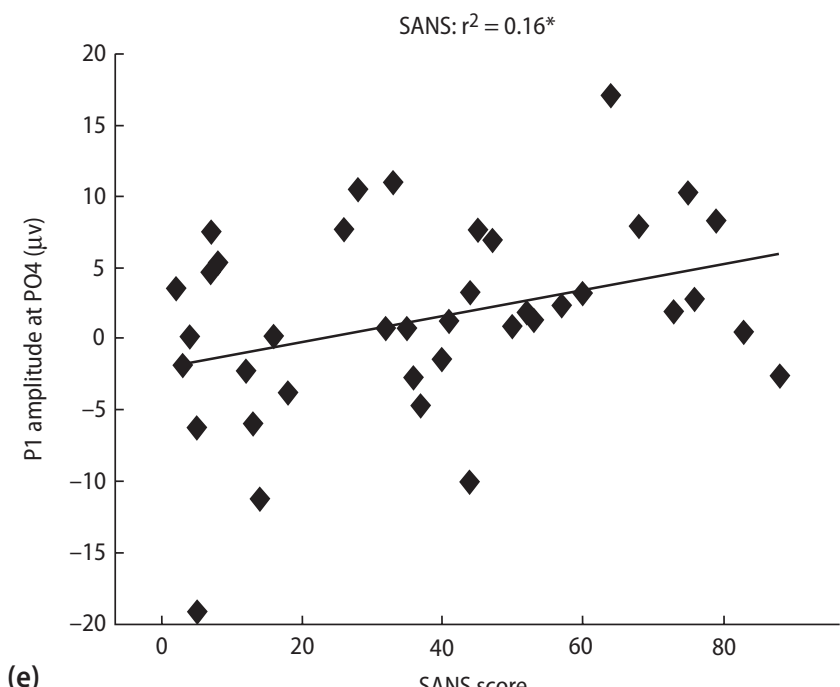

(e)

Fig. 4 Scatter plots showing a no correlation between P1 amplitude $(\mu \mathrm{V})$ and age (years), b no correlation between P1 and length of illness (years), $\mathbf{c}$ no correlation between P1 and medication as indexed by the chlorpromazine dose (mg/day), d a positive correlation between P1 and the Brief Psychiatric Rating Scale (BPRS) and e a positive correlation between P1 and Negative Symptoms (SANS). Asterisk denotes significance at the 0.05 level

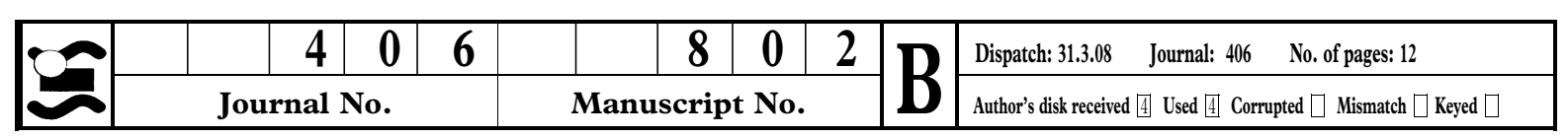


Fig. 5 Statistical cluster plot marking for all electrodes the time points at which the event-related potential differed significantly between groups on the basis of 2-tailed $t$ tests at an $\alpha$ level of 0.05 . Electrodes are ordered from top to bottom, occipital $(0)$, parieto-occipial $(P O)$, parietal $(P)$, centro-parietal $(C P)$, central $(C)$, fronto-central $(F C)$, frontal $(F)$ and anterior-fronto (AF) proceeding in an anterior direction in rows from left to right, to frontopolar (FP) sites at the top

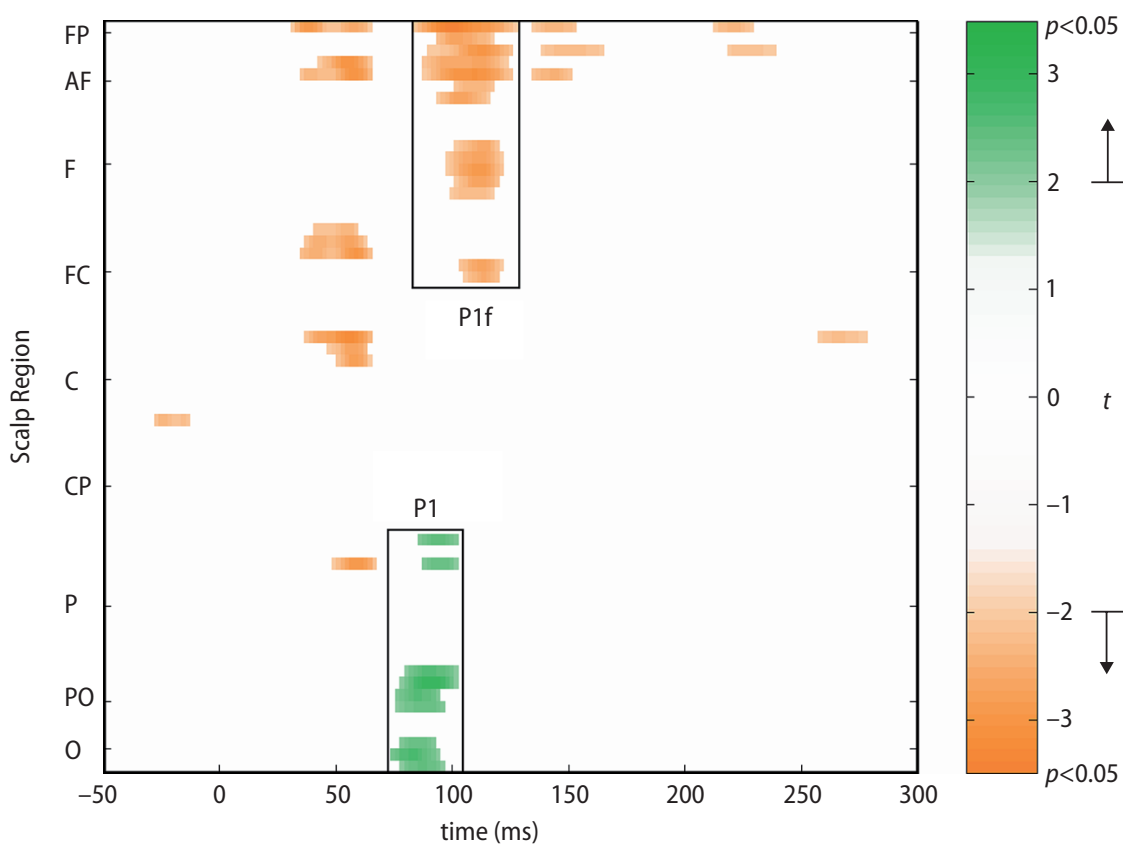

reason for not finding the $\mathrm{P} 1$ deficit in this minority of studies includes not focusing on scalp regions where the P1 is prominent (e.g. electrode site $\mathrm{Oz}$ in [64] and Johnston et al. 2005), since the P1 is best observed over more lateral-occipital scalp sites. Nonetheless, Strandburg et al. [63] did not find a significant P1 reduction in patients with schizophrenia in a visual detection task, nor did Bruder et al. [5] using a dot enumeration task. It is also possible that different methods of analysis may play a part in explaining the differences between the various studies [1]. Sponheim et al. [61] investigated P1 amplitude in the context of modulation of attention and perceptual load. Their study showed that schizophrenia patients failed to augment the $\mathrm{P} 1$ component during vigilance demands and concluded that this finding suggests a deficit in early processing of stimuli in patients. Although these eight studies did not find P1 deficits, as above, the large majority of studies where P1 was measured have. In many of these studies [28] the effect size was very large. All in all, the weight of evidence appears to overwhelmingly favour a robust $\mathrm{P} 1$ deficit in patients with schizophrenia.

\section{Age, length of illness, medication and symptomatology}

Only a handful of studies to date have directly looked at the relationship between early VEP and neuropsychological functioning and outcome. Schechter et al. [56] in an investigation aimed at parsing the Magnocellular and Parvocellular contributions to visual system functioning in schizophrenia also found the P1 deficit in patients. They then found significant correlation of the P1 deficit with global outcome and community functioning measures using the Independent Living Scale (ILS) [39]. However, no significant correlations between BPRS or SANS scores and any components of the VEP were found. Butler et al. [8] used the steady-state visual evoked potential (SSVEP) technique to investigate early stage visual processing deficits in schizophrenia. These investigators found deficits primarily in the magnocellular system as indexed by a reduction in contrast sensitivity and this deficit significantly correlated with poorer performance on the Digit Symbol task and with decreased IQ scores. No significant correlations were found with the Wisconsin Card Sorting task (WCS), a measure of cognitive control, or with the socalled and self-explanatory Logical Memory Tasks. Again, no correlation between SSVEP amplitude measures and clinical symptom scales (BPRS and SANS) was seen. The authors concluded that earlystage visual deficits contributed in turn to higher-level cognitive deficits. Spencer et al. [59] investigated gamma oscillatory and event related potential responses to Kaniza figures (figures that produce illusory contours) and also found deficits in patients with schizophrenia in the P1 component. This study did not attempt to correlate the VEP measures with clinical symptom scales but did find significant correlations between gamma responses over the occipital region and several positive symptoms (i.e. conceptual disorganization, visual hallucinations, thought withdrawal) and at parietal regions with negative symptoms. They did not find significant correlations with age, with age of onset or with medication dosage. Strandburg et al. [63] found no correlation between ERP measures and behavioural results during performance of a difficult visual discrimination task. They used the amplitude of the so-called 'Span

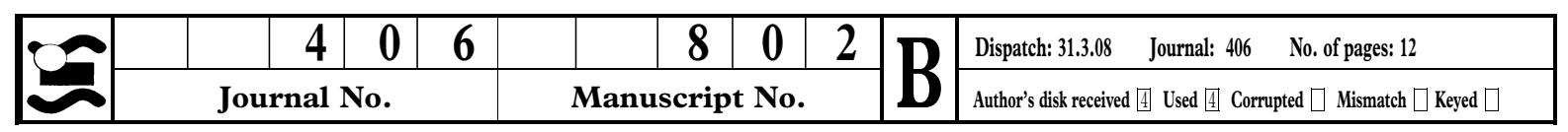



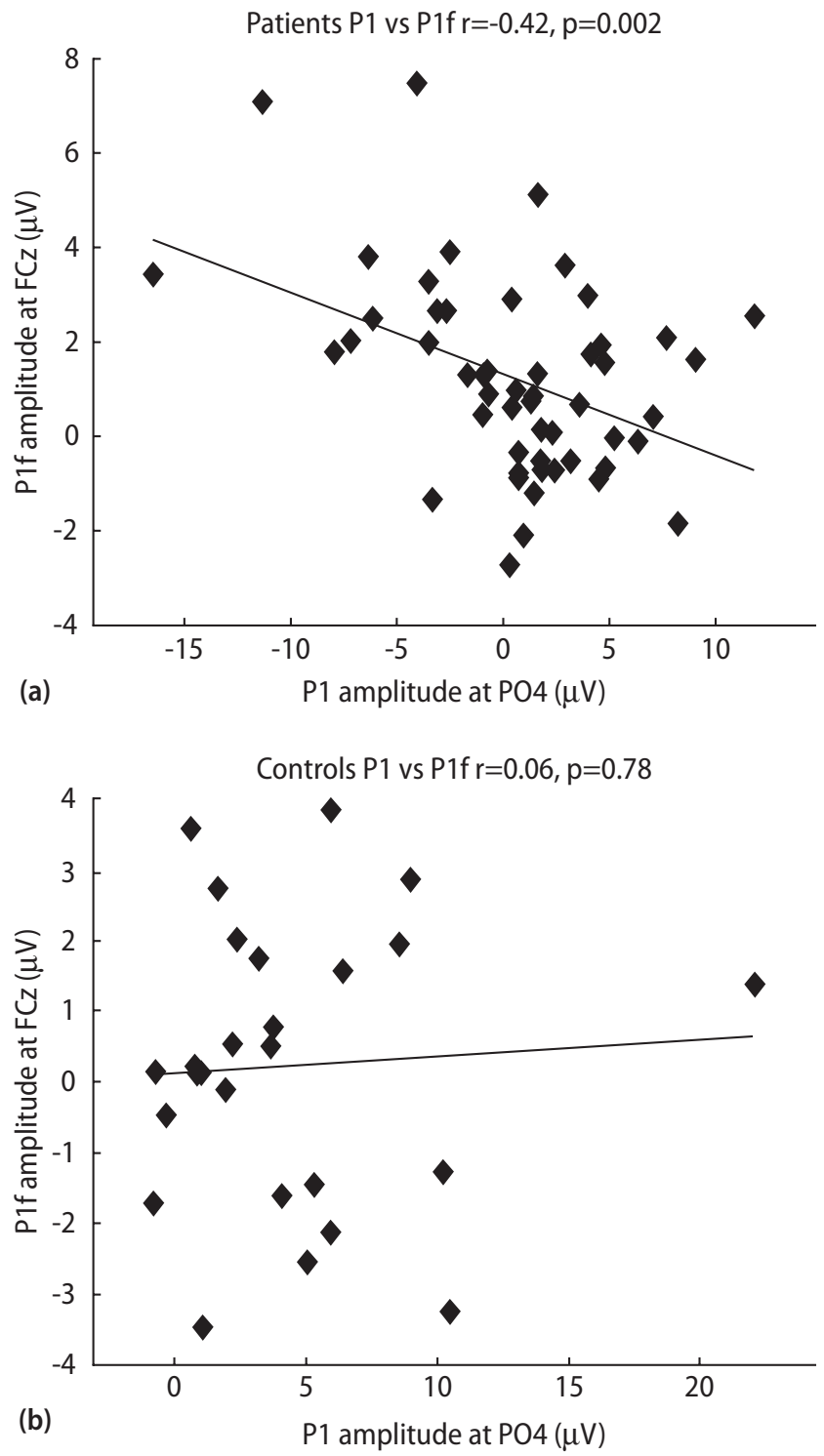

Fig. 6 Scatter plots of frontal positivity "P1f" against P1 for a patients and b controls

Negativity' component as their dependent measure, which is manifest as a relative negativity over parietal scalp during the timeframe of N1-P2 components. This 'Span Negativity' was not significantly correlated with IQ or clinical scales (BPRS or SANS scores). Bruder et al. [5] also found no correlation between ERP amplitudes and the total positive, negative and general psychopathology scores. They also reported no correlation with education level or age. Overall, one would have to conclude that measures of early visual processing in schizophrenia have not been found to correlate consistently with symptom scales.

In our study, there was a weak but significant positive correlation between the P1 amplitude and both BPRS and SANS scores. This finding is somewhat counter-intuitive. That is, one might predict that since P1 amplitude reduction appears to be a robust marker for schizophrenia, that greater deficits in this component would be associated with more severe forms of the disorder (i.e. higher scores on clinical scales). However, the correlation found here was an inverse one with patients who showed more preserved P1 amplitudes also recording the highest clinical scores. This finding will bear replicating before any firm conclusions can be reached. It is worth noting that the P1 amplitude accounted for only $11 \%$ of the variance in clinical measures, therefore over-interpretation is best avoided at this stage, especially in light of the fact that a number of previous studies have failed to find consistent correlations with symptomatology, albeit in smaller samples. Nonetheless, if the result holds, the implication is that although the P1 deficit may be related to risk for schizophrenia, it does not relate to the severity of the disorder once a person has succumbed. If anything, once sick with the disease, smaller P1 amplitudes appear to confer some protection against the severity of symptoms.

If $\mathrm{P} 1$ is a true trait marker, the prediction would be that the P1 impairment should remain largely constant across the lifespan, and this is what was found here. There was no correlation between the P1 amplitude and age of the patients. In addition, we wanted to determine whether P1 was associated with duration of the illness i.e. whether the deficit worsened over time. The results showed no correlation between length of illness and P1 amplitude.

Medication status has not been previously shown to correlate with VEP amplitudes [59, Butler et al. 1996]. Again, if P1 is a trait marker for schizophrenia, then medication status should play little or no role in its expression. Studies looking at unmedicated patient groups have also seen reductions in P1 amplitude [48] and we have seen P1 deficits in unmedicated healthy biological relatives [68], suggesting that medication does not in fact play a significant role. The results of this study are fully consistent with this notion, as we found no correlation whatsoever between P1 amplitude and antipsychotic dosage levels.

\section{The role of attention}

The difference in behavioural performance found here, with the control group scoring higher than the patient group, gives rise to the question, whether differences in the ability to maintain focused attention could have played a role in the present findings. However, even though previous studies have determined that attention effects can influence the amplitude of the P1 [30, 31, 40, 43, 54], the use of central presentations here helps to minimise the possible influence of attention [4]. The fact that patients detected the centrally presented targets with over $80 \%$ accuracy shows that they actively participated in the task and that they must have been centrally fixating as instructed. Handy and Khoe (2006) have shown that 2

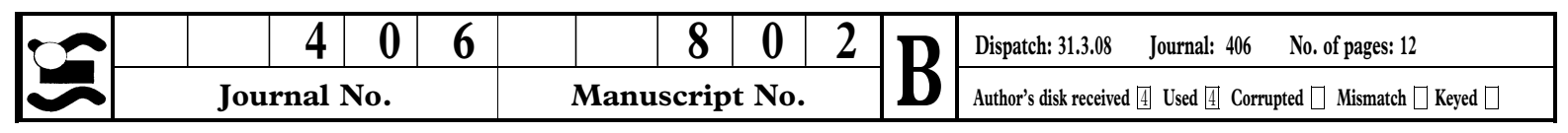


spatial attentional modulation of the P1 does not occur for transiently presented central stimuli. That is, they contended that stimuli presented to the foveal region appear to automatically engage attention. In a recent intersensory attention study, when subjects were concurrently asked to attend to a completely different sensory modality (e.g. auditory stimuli) the visual P1 remained unchanged [26].

Further, recent data from our laboratory [37] also make it unlikely that attentional factors play a significant role in the observed P1 deficit in schizophrenia. In that study, we used a novel visual evoked potential technique (which we have termed the VESPA - for visual evoked spread spectrum analysis) to preferentially evoke activity in the parvocellular system, one of the two major visual cellular divisions. A striking pattern of results was obtained. First, using the standard VEP technique, a significantly reduced P1 component was found once again in patients (with a very large effect size; Cohen's $d=1.6$ ). However, an assessment of parvocellular functioning using the VESPA showed identical P1 responses for both patients and controls. It seems very unlikely that attention or arousal mechanisms would so completely affect one cellular system and not the other. Nor can this finding be ascribed to a lack of attentional modulability of the VESPA P1 since Lalor et al. [35] showed clear modulation thereof during a spatial attention task. As such, the present results do not easily lend themselves to a differential attentional account.

\section{Hyperfrontality}

A clear positive going ERP component (which we termed P1f here) was observed over midline frontal sites in patients over the time period immediately following the occipital P1 ( 105-120 ms), an effect barely observable in healthy control subjects. That this component was significantly enhanced in patients raises the possibility that some recruitment of frontal regions may occur in schizophrenia to compensate for basic deficiencies in early visual sensory processing. This notion receives some measure of support from the finding that the amplitude of this P1f was inversely correlated with the amplitude of the occipital P1. That is, the weaker the posterior P1, the larger the frontal component was in schizophrenia patients, and this was not the case for healthy control subjects. This finding is decidedly reminiscent of observations in the aging literature, where a similar "compensation hypothesis" has been invoked to explain consistent findings of increased frontal activation in high-functioning older adults performing a variety of cognitive tasks [6, 10-13, 20, 38). Increased frontal activation has also been seen in healthy aging adults during basic sensory stimulation [19], so the finding of frontal hyper-activation does not require active participation in a demanding cognitive task. It should also be pointed out that we have found similar frontal hyper-activation in a number of our previous studies in patients with schizophrenia [21, 26].

An alternate account for this hyper-activation may lie in the neurochemical underpinnings of the $\mathrm{P} 1$ component. While surprisingly little is known about the underlying neurophysiology of the major human VEP components, electrophysiological work by Zemon et al. [69] in anaesthetized cats suggested that the P1 component of the VEP might represent an intracortical inhibitory process-that is, that it is largely GABAergic (gamma-aminobutyric acidergic) in origin. Using topical application of bicuculline, a GABAergic antagonist, the authors showed a substantial decrease in the amplitude of the first major positive component of the cat VEP (a putative homologue of the human visual P1). One implication of these results, insofar as they can be reasonably applied to recordings in humans, is that a failure of normal posterior inhibition might in turn allow for increased transmission of signals into higher-order frontal regions, resulting in hyper-activation of structures that under normal circumstances should not be activated in response to simple non-target stimuli. That is, one might hypothesize that a function of the processing represented by the $\mathrm{P} 1$ is to arrest anteriorization of signals when incoming stimuli are irrelevant to task performance and need not be processed further. An upshot of failure of this inhibitory function would be the unnecessary activation of frontal control regions that should be otherwise engaged in higher-order processing, potentially leading to cognitive disorganization. Clearly this is speculative and it should be pointed out that the P1 deficit has also been linked to excitatory (n-methyld-aspartate (NMDA)) functioning (see [9]). It will take pharmacological manipulations to disentangle the contributions of the various receptor systems to P1 processing.

\section{Conclusions}

The finding of a substantially reduced $\mathrm{P} 1$ in this large unique cohort adds to a growing body of evidence for early visual sensory processing dysfunction in patients with schizophrenia. This P1 deficit is independent of age, length of illness and medication status, reinforcing the notion that the $\mathrm{P} 1$ is a trait marker for the disease and may serve as a useful index of genetic liability for schizophrenia.

\footnotetext{
Acknowledgments The authors would like to express their sincere gratitude to the Chief Executive Officer at St. Vincent's Hospital, Mr. Edward Byrne and to the Director of Nursing, Mrs. Phil Burke, for their ongoing and essential support of the Cognitive Neurophysiology Laboratory. Thanks also go to Micheál Mac an tSionnaigh for his help in establishing and maintaining the laboratory, and to the nursing staff at St. Vincent's hospital for their
}

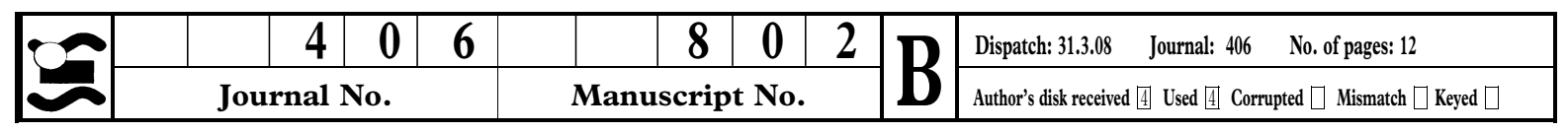


dedication to the patients and their ongoing support of this work. Grant Support: This work was supported in part by an RO1 grant from the U.S. National Institute of Mental Health (NIMH) to Professor Foxe (MH65350). Dr. Yeap was supported by a fellowship from the Irish Health Research Board (HRB). Dr. Magno was supported by a fellowship from the Irish Research Council for the Humanities and Social Sciences (IRCHSS).

\section{References}

1. Alain C, Hargrave R, Woods DL (1998) Processing of auditory stimuli during visual attention in patients with schizophrenia. Biol Psychiatry 44(11):1151-1159

2. Andreasen NC (1983) The scale for the assessment of negative symptoms (SANS). Department of Psychiatry, University of Iowa, Iowa City

3. Basinska A (1998) Altered electrophysiological pattern of target detection in schizophrenia in the continuous attention test. Acta Neurobiol Exp (Wars) 58(3):207-220

4. Birkett P, Brindley A, Norman P, Harrison G, Baddeley A (2006) Control of attention in schizophrenia. J Psychiatr Res 40(7):579-588

5. Bruder G, Kayser J, Tenke C, Rabinowicz E, Friedman M, Amador X, Sharif Z, Gorman J (1998) The time course of visuospatial processing deficits in schizophrenia: an eventrelated brain potential study. J Abnorm Psychol 107(3): 399-411

6. Buckner RL (2004) Memory and executive function in aging and $\mathrm{AD}$ : multiple factors that cause decline and reserve factors that compensate. Neuron 44(1):195-208

7. Butler PD, Schechter I, Zemon V, Schwartz SG, Greenstein VC, Gordon J, Schroeder CE, Javitt DC (2001) Dysfunction of earlystage visual processing in schizophrenia. Am J Psychiatry 158(7):1126-1133

8. Butler PD, Zemon V, Schechter I, Saperstein AM, Hoptman MJ, Lim KO, Revheim N, Silipo G, Javitt DC (2005) Early-stage visual processing and cortical amplification deficits in schizophrenia. Arch Gen Psychiatry 62(5):495-504

9. Butler PD, Martinez A, Foxe JJ, Kim D, Zemon V, Silipo G, Mahoney J, Shpaner M, Jalbrzikowski M, Javitt DC (2007) Subcortical visual dysfunction in schizophrenia drives secondary cortical impairments. Brain 130 (Pt 2):417-430

10. Cabeza R, Anderson ND, Houle S, Mangels JA, Nyberg L (2000) Age-related differences in neural activity during item and temporal-order memory retrieval: a positron emission tomography study. J Cogn Neurosci 12(1):197-206

11. Cabeza $R$ (2002) Hemispheric asymmetry reduction in older adults: the HAROLD model. Psychol Aging 17(1):85-100

12. Cabeza R, Anderson ND, Locantore JK, McIntosh AR (2002) Aging gracefully: compensatory brain activity in high-performing older adults. Neuroimage 17(3):1394-1402

13. Cabeza R, Daselaar SM, Dolcos F, Prince SE, Budde M, Nyberg L (2004) Task-independent and task-specific age effects on brain activity during working memory, visual attention and episodic retrieval. Cereb Cortex 14(4):364-375

14. Clarke M, O'Callaghan E (2003) Is earlier better? At the beginning of schizophrenia: timing and opportunities for early intervention. Psychiatr Clin North Am 26(1):65-83

15. Clarke M, Whitty P, Browne S, McTigue O, Kamali M, Gervin M, Kinsella A, Waddington JL, Larkin C, O'Callaghan E (2006) Untreated illness and outcome of psychosis. Br J Psychiatry 189:235-240

16. Clementz BA, Keil A, Kissler J (2004) Aberrant brain dynamics in schizophrenia: delayed buildup and prolonged decay of the visual steady-state response. Brain Res Cogn Brain Res 18(2):121-129

17. Cohen J (1988) Statistical power analysis for the behavioral sciences, 2nd edn. Lawrence Erlbaum Associates Publishers, Hillsdale, pp 8-13
18. Davenport ND, Sponheim SR, Stanwyck JJ (2006) Neural anomalies during visual search in schizophrenia patients and unaffected siblings of schizophrenia patients. Schizophr Res 82(1):15-26

19. De Sanctis P, Katz R, Wylie GR, Sehatpour P, Alexopoulos GS, Foxe JJ (2007) Enhanced and bilateralized visual sensory processing in the ventral stream may be a feature of normal aging. Neurobiol [Epub ahead of print]

20. DiGirolamo GJ, Kramer AF, Barad V, Cepeda NJ, Weissman DH, Milham MP, Wszalek TM, Cohen NJ, Banich MT, Webb A, Belopolsky AV, McAuley E (2001) General and task-specific frontal lobe recruitment in older adults during executive processes: a fMRI investigation of task-switching. Neuroreport 12(9):2065-2071

21. Doniger GM, Foxe JJ, Murray MM, Higgins BA, Javitt DC (2002) Impaired visual object recognition and dorsal/ventral stream interaction in schizophrenia. Arch Gen Psychiatry 59(11):10111020

22. Donohoe G, Morris DW, De Sanctis P, Magno E, Montesi JL, Garavan HP, Robertson IH, Javitt DC, Gill M, Corvin AP, Foxe JJ (2007) Early visual processing deficits in dysbindin-associated Schizophrenia. [Epub ahead of print]

23. Foxe JJ, Doniger GM, Javitt DC (2001) Early visual processing deficits in schizophrenia: impaired P1 generation revealed by high-density electrical mapping. Neuroreport 12(17):3815-3820

24. Foxe JJ, Simpson GV (2002) Flow of activation from V1 to frontal cortex in humans. A framework for defining early visual processing. Exp Brain Res 142(1):139-150

25. Foxe JJ, Simpson GV (2005a) Biasing the brain's attentional set: II. effects of selective intersensory attentional deployments on subsequent sensory processing. Exp Brain Res 166(3-4):393401

26. Foxe JJ, Murray MM, Javitt DC (2005b) Filling-in in Schizophrenia: a high-density electrical mapping and source-analysis investigation of illusory contour processing. Cereb Cortex 15(12):1914-1927

27. Gottesman II, Gould TD (2003) The endophenotype concept in psychiatry: etymology and strategic intentions. Am J Psychiatry 160(4):636-645

28. Haenschel C, Bittner MA, Haertling F, Rotarska-Jagiela A, Maurer K, Singer W, Linden DEJ (2007) Contribution of impaired early-stage visual processing to working memory dysfunction in adolescents with schizophrenia-a study with event-related potentials and functional magnetic resonance imaging. Arch Gen Psychiatry 64(11):1229-1240

29. Handy TC, Khoe W (2005) Attention and sensory gain control: a peripheral visual process? J Cogn Neurosci 17(12): 1936-1349

30. Heinze HJ, Luck SJ, Mangun GR, Hillyard SA (1990) Visual event-related potentials index focused attention within bilateral stimulus arrays. I. Evidence for early selection. Electroencephalogr Clin Neurophysiol 75(6):511-527

31. Heinze HJ, Mangun GR, Burchert W, Hinrichs H, Scholz M, Munte TF, Gos A, Scherg M, Johannes S, Hundeshagen $\mathrm{H}$ et al (1994) Combined spatial and temporal imaging of brain activity during visual selective attention in humans. Nature 372(6506):543-546

32. Katsanis J, Iacono WG, Beiser M (1996) Visual event-related potentials in first-episode psychotic patients and their relatives. Psychophysiology 33(3):207-217

33. Keri S, Kelemen O, Janka Z, Benedek G (2005) Visual-perceptual dysfunctions are possible endophenotypes of schizophrenia: evidence from the psychophysical investigation of magnocellular and parvocellular pathways. Neuropsychology 19(5):649-656

34. Kim D, Wylie G, Pasternak R, Butler PD, Javitt DC (2006) Magnocellular contributions to impaired motion processing in schizophrenia. Schizophr Res 82(1):1-8

35. Lalor EC, Kelly SP, Pearlmutter BA, Reilly RB, Foxe JJ (2007) Isolating endogenous visuo-spatial attentional effects using the novel visual-evoked spread spectrum analysis (VESPA) technique. Eur J Neurosci 26(12):3536-3542

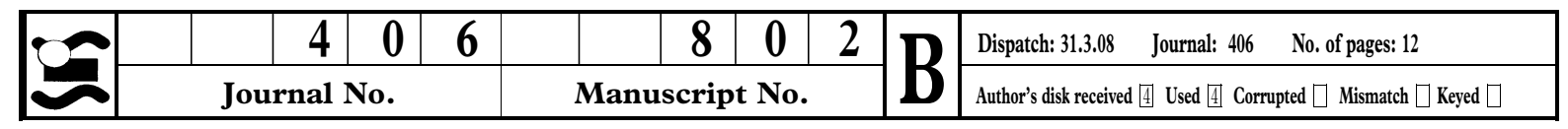


36. Lalor EC, Pearlmutter BA, Reilly BA, Foxe JJ (2006) The VESPA: a method for the rapid estimation of a visual evoked potential. Neuroimage 32(4):1549-1561

37. Lalor EC, Yeap S, Reilly RB, Pearlmutter BA, Foxe JJ (2008) Dissecting the cellular contributions to early visual sensory processing deficits in schizophrenia using the VESPA evoked response. Schizophr Res 98(1-3):256-264

38. Langenecker SA, Nielson KA, Rao SM (2004) fMRI of healthy older adults during Stroop interference. Neuroimage 21(1):192200

39. Loeb PA, Fe R (1996) ILS: Independent living scales manual. The Psychological Corporation, Harcourt Race Jonanovich, Inc, San Antonio

40. Luck SJ, Heinze HJ, Mangun GR, Hillyard SA (1990) Visual event-related potentials index focused attention within bilateral stimulus arrays. II. Functional dissociation of P1 and N1 components. Electroencephalogr. Clin Neurophysiol 75(6):528542

41. Malla AK, Norman RM, Manchanda R, Ahmed MR, Scholten D, Harricharan R, Cortese L, Takhar J (2002) One year outcome in first episode psychosis: influence of DUP and other predictors. Schizophr Res 54(3):231-242

42. Mangun GR, Buonocore MH, Girelli M, Jha AP (1998) ERP and fMRI measures of visual spatial selective attention. Hum Brain Mapp 6(5-6):383-389

43. Martinez A, Anllo-Vento L, Sereno MI, Frank LR, Buxton RB, Dubowitz DJ, Wong EC, Hinrichs H, Heinze HJ, Hillyard SA (1999) Involvement of striate and extrastriate visual cortical areas in spatial attention. Nat Neurosci 2(4):364-369

44. Matsuoka H, Saito H, Ueno T, Sato M (1996) Altered endogenous negativities of the visual event-related potential in remitted schizophrenia. Electroencephalogr Clin Neurophysiol 100(1):18-24

45. McCourt ME, Shpaner M, Javitt DC, Foxe JJ (2008) Hemispheric asymmetry and callosal integration of visuospatial attention in schizophrenia: a tachistoscopic line bisection study. Schizophr Res (in press)

46. Merigan WH, Maunsell JH (1993) How parallel are the primate visual pathways? Annu Rev Neurosci 16:369-402

47. Molholm S, Ritter W, Murray MM, Javitt DC, Schroeder CE, Foxe JJ (2002) Multisensory auditory-visual interactions during early sensory processing in humans: a high-density electrical mapping study. Brain Res Cogn Brain Res 14:115-128

48. Mukundan CR (1986) Middle latency components of evoked potential responses in schizophrenics. Biol Psychiatry 21(11):1097-1100

49. Murray MM, Foxe JJ, Higgins BA, Javitt DC, Schroeder CE (2001) Visuo-spatial neural response interactions in early cortical processing during a simple reaction time task: a high-density electrical mapping study. Neuropsychologia 39(8):828-844

50. Oldfield RC (1971) The assessment and analysis of handedness: the Edinburgh inventory. Neuropsychologia 9:97-113

51. Overall JE, Gorham DR (1962) The brief psychiatric rating scale. Psychol Rep 10:799-812

52. Perrin F, Pernier J, Bertrand O, Echallier JF (1989) Spherical splines for scalp potential and current density mapping. Electroencephalogr Clin Neurophysiol 72:184-187

53. Romani A, Zerbi F, Mariotti G, Callieco R, Cosi V (1986) Computed tomography and pattern reversal visual evoked potentials in chronic schizophrenic patients. Acta Psychiatr Scand 73(15):566-573
54. Rugg MD, Milner AD, Lines CR, Phalp R (1987) Modulation of visual event-related potentials by spatial and non-spatial visual selective attention. Neuropsychologia 25(1A):85-96

55. Schechter I, Butler PD, Silipo G, Zemon V, Javitt DC (2003) Magnocellular and parvocellular contributions to backward masking dysfunction in schizophrenia. Schizophr Res 64(2-3): 91-101

56. Schechter I, Butler PD, Zemon VM, Revheim N, Saperstein AM, Jalbrzikowski M, Pasternak R, Silipo G, Javitt DC (2005) Impairments in generation of early-stage transient visual evoked potentials to magno- and parvocellular-selective stimuli in schizophrenia. Clin Neurophysiol 116(9):2204-2215

57. Schwartz BD, Tomlin HR, Evans WJ, Ross KV (2001) Neurophysiologic mechanisms of attention: a selective review of early information processing in schizophrenics. Front Biosci 6:D120134

58. Spencer KM, Nestor PG, Niznikiewicz MA, Salisbury DF, Shenton ME, McCarley RW (2003) Abnormal neural synchrony in schizophrenia. J Neurosci 23(19):7407-7411

59. Spencer KM, Nestor PG, Perlmutter R, Niznikiewicz MA, Klump MC, Frumin M, Shenton ME, McCarley RW (2004) Neural synchrony indexes disordered perception and cognition in schizophrenia. Proc Natl Acad Sci USA 101(49):1728817293

60. Spitzer RL, Williams JB, Gibbon M, First MB (1992) The Structured Clinical Interview for DSM-III-R (SCID). I: History, rationale, and description. Arch Gen Psychiatry 49(8): 624-629

61. Sponheim SR, McGuire KA, Stanwyck JJ (2006) Neural anomalies during sustained attention in first-degree biological relatives of schizophrenia patients. Biol Psychiatry 60(3): 242-252

62. Steinman BA, Steinman SB, Lehmkuhle S (1997) Transient visual attention is dominated by the magnocellular stream. Vision Res 37(1):17-23

63. Strandburg RJ, Marsh JT, Brown WS, Asarnow RF, Guthrie D, Higa J, Yee-Bradbury CM, Nuechterlein KH (1994) Reduced attention-related negative potentials in schizophrenic adults. Psychophysiology 31(3):272-281

64. van der Stelt O, Frye J, Lieberman JA, Belger A (2004) Impaired P3 generation reflects high-level and progressive neurocognitive dysfunction in schizophrenia. Arch Gen Psychiatry 61(3):237-248

65. Van Sweden B, Van Erp MG, Mesotten F, Crevits L (1998) Impaired early visual processing in disorganised schizophrenia. Acta Neurol Belg 98(1):17-20

66. Vidyasagar TR (1999) A neuronal model of attentional spotlight: parietal guiding the temporal. Brain Res Brain Res Rev 30(1):66-76

67. Wylie GR, Javitt DC, Foxe JJ (2003) Task switching: a high-density electrical mapping study. Neuroimage 20(4):22322242

68. Yeap S, Kelly SP, Sahatpour P, Magno E, Garavan H, Javitt DS, Thakore JH, Foxe JJ (2006) Early visual sensory deficits as endophenotypes for schizophrenia: high density electrical mapping in clinically unaffected first-degree relatives. Arch Gen Psych 63(11):1180-1188

69. Zemon V, Kaplan E, Ratliff F (1980) Bicuculline enhances a negative component and diminishes a positive component of the visual evoked cortical potential in the cat. Proc Natl Acad Sci USA 77(12):7476-7478

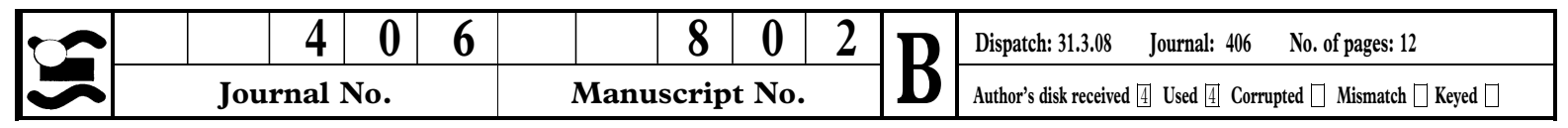




\section{Author Query Form}

Journal : 406

Article No. : 802

Dear Author,

During the copy-editing of your paper, the following queries arose. Please respond to these by marking up your proofs with the necessary changes/additions. Please write your answers on the query sheet if there is insufficient space on the page proofs. Please write clearly. If returning the proof by fax do not write too close to the paper's edge. Please remember that illegible mark-ups may delay publication.

\section{Author Queries}

\begin{tabular}{|l|l|l|}
\hline \multicolumn{1}{|c|}{ Query reference } & \multicolumn{1}{|c|}{ Query } & Remarks \\
\hline 1 & $\begin{array}{l}\text { Handy and Khoe (2006) is cited in text but missing in } \\
\text { list. please provide the reference details. }\end{array}$ & \\
\hline 2 & $\begin{array}{l}\text { Handy and Khoe (2006) is cited in text but missing in } \\
\text { list. please provide the reference details. }\end{array}$ & \\
\hline 3 & Please update the reference. & \\
\hline
\end{tabular}

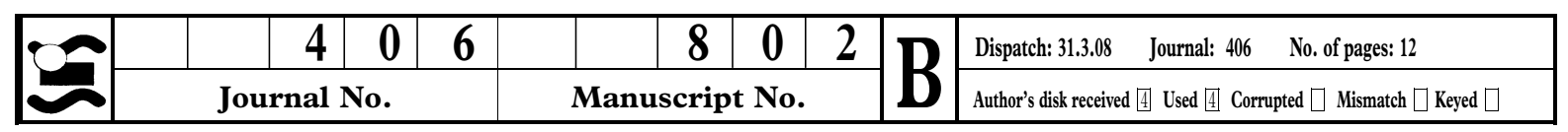

